\title{
Lamberto Perugia Lecture The intuition and contribution of Lamberto Perugia and his fellows to anterior cruciate ligament reconstruction
} Lecture given to the $1^{\text {st }}$ European Workshop on Ligaments and Tendons Arezzo October $19^{\text {th }}, 2013$

\author{
ANDREA FERRETTI
}

Department of Orthopaedics, $2^{\text {nd }}$ School of Medicine, "Sapienza" University of Rome, Division of Orthopaedics, Sant'Andrea University Hospital, Rome, Italy

Colleagues, first of all, I wish to thank the presidents of this congress for giving me the opportunity to speak to you in memory of my teacher and mentor, Professor Lamberto Perugia.

Although some of Professor Perugia's fellows went on to achieve professional and academic success in various other branches of the orthopaedic sciences, the field he particularly loved was that of sports medicine, probably as a result of his passion for sport, which can be traced back to his time as a basketball player for S.S. Lazio, and to the time when, just few months after his graduation, he joined the newly founded Federazione Medico Sportiva Italiana.

Among Professor Perugia's distinguished fellows in the field of sports medicine and arthroscopy, it is a great pleasure for me to mention Giancarlo Puddu, who has a place in the American Orthopaedic Society for Sports Medicine (AOSSM) Hall of Fame, and Pierpaolo Mariani, who probably boasts the largest series of anterior cruciate ligament (ACL) reconstructions performed in professional football players.

The first intra-articular ACL reconstruction performed in the $2^{\text {nd }}$ Orthopaedic Clinic of the University of Rome was done in November 1979 by Giancarlo Puddu, who, under Perugia's guidance, developed an original method of ACL reconstruction using the semitendinosus tendon (1). Perugia himself later sug-

Corresponding Author:

Andrea Ferretti, MD

Division of Orthopaedics, Sant'Andrea University Hospital

Via di Grottarossa 1035 Rome, Italy

E-mail: aferretti51@virgilio.it gested adding the gracilis in order to make the graft even stronger.

Another of Professor Perugia's particular interests was anatomy and, in ACL reconstruction, he was always a firm believer in anatomical placement of the graft with positioning of its femoral attachment far posterior to the lateral condyle (Fig. 1). This "dark" site was approached by means of a smart and simple guide invented by Puddu which, thanks to its offset, allowed the surgeon, even in the pre-arthroscopic era (when reconstructions were performed in an open fashion) to reproducibly place the graft in its anatomical site just in front of the over-the-top position (Fig. 2).

Recent studies performed by our group (2) confirmed that an anatomically placed anteromedial (AM) bundle matches the anatomy and function of the normal $\mathrm{ACL}$, and that adding a posterolateral (PL) bundle to

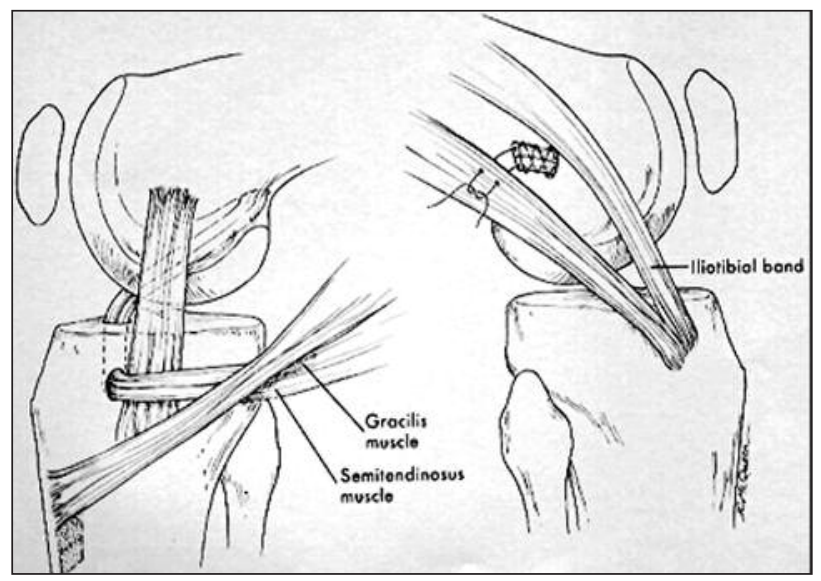

Fig. 1. The method of ACL reconstruction using semitendinosus and gracilis developed by Puddu, as featured in an old version of the Campbell Orthopaedics Textbook. 

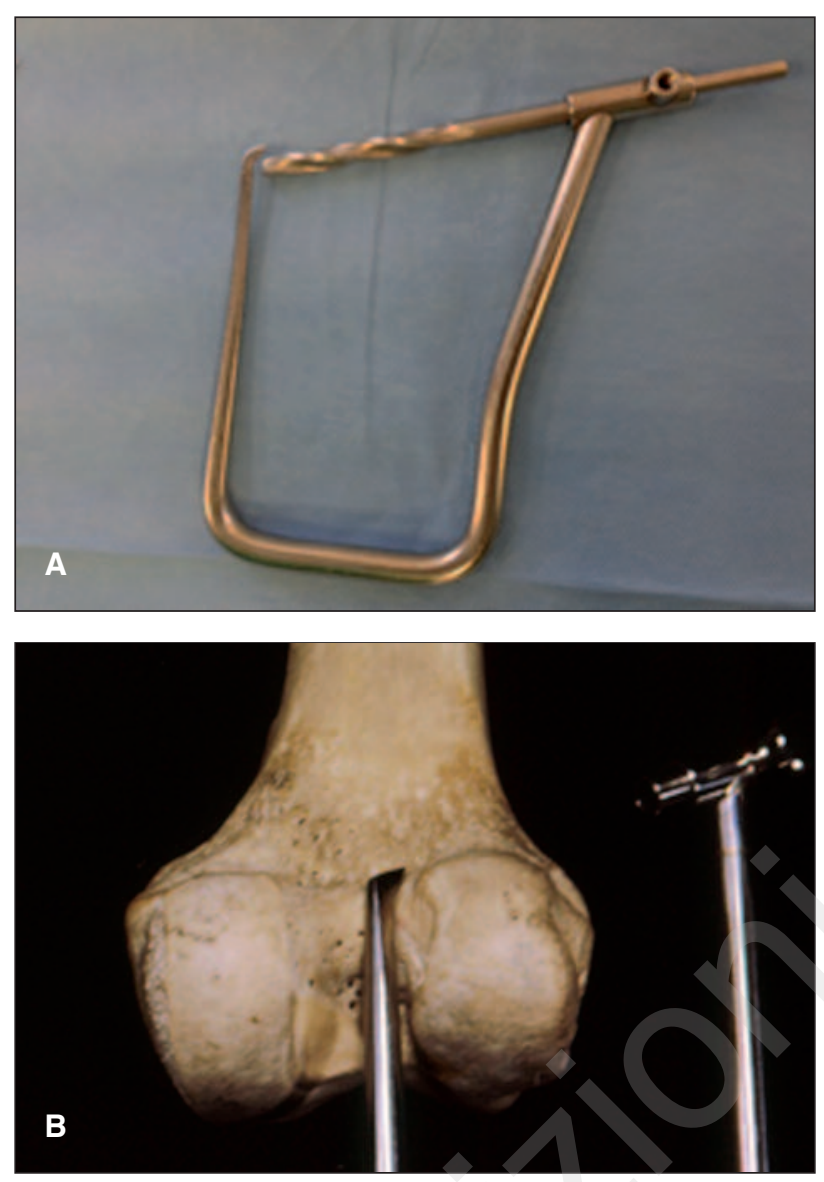

Fig. 2. The offset "Puddu" guide for femoral tunnel drilling (A). The guide allows to place the graft in its anatomical site just in front of the "over the top" position (B).

an AM bundle, as recently suggested by Freddy Fu, is of little, in any, value.

As Professor Perugia used to say, so-called non-anatomical reconstructions could simply be called incorrect reconstructions!

But why did Lamberto Perugia go on favoring the use of hamstring tendons (HTs) even when, in the 1980s, most orthopaedic surgeons were choosing the bonepatellar tendon-bone (BPTB) graft as the gold standard? The reasons for his choice were anatomical, biological, biomechanical and surgical.

From the anatomical perspective, HT graft better matches the length, width, bundles and cross-sectional area of the native ACL.

The biology of HTs differs from that of the BPTB, as HTs inhabit a synovial environment. Therefore, HTs do not change their environment when they are transplanted intra-articularly. In fact, they are not subject to the kind of vascular crisis described by Arnoczky et al. in relation to a BPTB graft (3).

Although it is well known that, compared with HTs, the bone plugs of BPTB grafts heal faster inside the bone tunnels, when a proper fixation device is used, valid direct tendon-bone healing can nevertheless occur at the HT graft tibia interface, thanks to the formation of strong Sharpey's fibers. Quite surprisingly, in a recent study presented to the American Academy of Orthopaedic Surgeons, we showed that in more than one third of cases of reconstructions based on BPTB grafts, the bone plug is actually resorbed, precluding proper healing (4). It is possible that, in these cases, healing occurs at the tendon-bone interface, as with the HT graft, but the mismatch between the diameter of the graft and the tunnel results in fibrous tissue formation. Therefore, the real advantage of BPTB over HTs should be questioned.

Biomechanical studies have shown that a four-strand HT graft with all four strands equally tensioned is stronger and stiffer than the native ACL.

The biomechanical properties of the graft fixation devices have been considered an issue for HTs as compared with the BPTB graft, whose fixation tend to be considered stronger and stiffer.

However, biomechanical studies performed by our group on many fixation devices and on the whole fixation-graft complex revealed that many of the currently used fixation methods for HT graft have excellent properties, even better than those used for the BPTB graft (5).

The use of HTs has also become widespread among knee surgeons due to its surgical advantages, which include lack of interference with the extensor mechanism, reduced risk of postoperative complications and arthrofibrosis, and minimized morbidity. Even in acute cases treatment of associated injuries can be performed uneventfully.

Excellent functional recovery can be due to the potential for regeneration offered by the semitendinosus and documented by imaging, functional and histological studies (6-8). Another brilliant intuition of Professor Perugia was his use of peripheral plasties in place of or to support intra-articular reconstruction. 
Following a visit to Columbus, Georgia, Professor Perugia, embracing the theories of Jack Hughston, began using several extra-articular reconstruction techniques, both passive and active: advancement of the posterior oblique ligament, iliotibial tract tenodesis according to Andrews, advancement of the semi-membranosus and biceps, and the modified McIntosh technique as developed by Coker and later published by Arnold et al. (9); on the basis of 30 years' experience and an excellent biomechanical study (10), the latter technique is still successfully used in our department in selected cases of severe instability, in at-risk athletes (especially women), and in revisions.

Professor Perugia should be credited with having lent his strong support to these techniques even when, in the USA, most authors given up on them as a result of a misleading publication by the AOSSM, whose conclusions were based on outdated opinions (11).

Confirmation of the value of Professor Perugia's experience and teaching was recently provided by a review of a series of 100 cases operated on according to the technique in use in our center (developed according to the principles of Professor Perugia) and reviewed at long-term follow-up.

The overall rate of clinical and radiological success was $>90 \%$, and even greater in cases in which, in spite of a higher preoperative level of sports activity and a higher grade of instability, a lateral reconstruction was added. These results may probably be considered the best legacy of Professor Perugia's teaching.

I always addressed Professor Perugia in the third person, a respectful form of address that has no equivalent in English. Indeed, I held him in the highest regard, and all I wish to say now, by way of a conclusion, is how very much he is missed.

\section{References}

1. Puddu G. Method for reconstruction of the anterior cruciate ligament using semitendinosus tendon. Am J Sports Med 1980; 8:402-404.

2. Ferretti A, Monaco E, Labianca L, et al. Double-bundle anterior cruciate ligament reconstruction: a computer assisted orthopaedic surgery study. Am J Sports Med 2008; 36:760766.

3. Arnoczky SP, Tarvin GB, Marshall JL. Anterior cruciate ligament replacement using patellar tendon. An evaluation of graft revascularization in the dog. J Bone Joint Surg Am 1982; 64:217-224.

4. Iorio R, Redler A, Mazza D, et al. Biological fixation of the bone graft in ACL reconstruction with BPTB: does the bone plug really heal inside the tibial tunnel? Proceedings AAOS Annual Meeting of AAOS, San Diego, 2011.

5. Monaco E, Labianca L, Speranza A, et al. Biomechanical evaluation of different anterior cruciate ligament fixation techniques for hamstring graft. J Orthop Sci 2010; 15:125-131.

6. Papandrea P, Vulpiani MC, Ferretti A, et al. Regeneration of the semitendinosus tendon harvested for anterior cruciate ligament reconstruction. Evaluation using ultrasonography. Am J Sports Med 2000; 28:556-561.

7. Ferretti A, Conteduca F, Morelli F, et al. Regeneration of semitendinosus tendon after its use in anterior cruciate ligament reconstruction: a histologic study of three cases. Am J Sports Med 2002; 30:204-207.

8. Papandrea P, De Carli A, Lucente L, et al. Capacité de saut chez les athlètes opérés de reconstruction du ligament croisé antérieur. J Traumatol Sport 1990; 7:76-79.

9. Arnold JA, Coker TP, Heaton LM, et al. Natural history of anterior cruciate tears. Am J Sports Med 1979; 7:305-313.

10. Ferretti A, Monaco E, Labianca L, et al. Double bundle or single bundle plus extra-articular tenodesis in ACL reconstruction? A CAOS study. Knee Surg Sports Traumatol Arthrosc 2007; 15:1168-74.

11. Pearl A, Bergfeld JA. Extraarticular Reconstruction in the ACL deficient Knee. Human Kinetics, Champaign 1992. 